\title{
Planned Chaos in Electrical Engineering Education
}

\section{Thomas Fuhrmann, Michael Niemetz}

Faculty of Electrical Engineering and Information Technology, OTH Regensburg, Seybothstrasse 2, Regensburg, Germany.

\begin{abstract}
This paper presents the idea to intentionally introduce planned chaos into electrical engineering lectures and lab courses to improve students' learning success. The reason to present this idea are several personal experiences in daily teaching. If students experience some uncertainty in their study program, it is seen that they have higher challenges and therefore higher learning success in managing uncertain situations. In these ways, students acquire methodical and social competences to deal with uncertainty and achieve productive results in an unstable working environment. If, however, the chaos is too large, students are over-strained with the situation, distracted from the actual learning targets and consequently learning results will be worse, drop-out rates will increase and they will be frustrated. The beneficial level of uncertainty depends on the student culture, academic progress and personality characteristics. The competence to deal with complex situations is essential for later professional life where unexpected circumstances occur regularly. Introducing planned chaos into lectures and lab courses has not to be confused with a missing didactic concept and is no justification for a bad preparation. Planned chaos is a demanding concept for professors to find the right implementation for an optimized learning outcome. These described findings are experienced from practical work and student evaluations.
\end{abstract}

Keywords: Electrical Engineering Education, Active Learning, Planned Chaos. 


\section{Introduction and Motivation}

OTH Regensburg is a German University of Applied Sciences with a strong focus on the region of Eastern Bavaria but also with partnerships all over the world. The key area of this university is to educate young people mainly from the region of Eastern Bavaria to qualify them for work in companies and institutions. On top of this, the second emphasis is on applied research in connection with companies.

OTH Regensburg has many alumni who are very successful in their professional careers. They work on innovative topics in companies and institutions, do research and development, manage companies or start their own business. Not the grades on a diploma certificate but the success of the alumni in their later life is the outcome of a successful study program. Therefore, it is important to prepare students for their later professional life that is unforeseeable and maybe sometimes chaotic. This is the motivation for the idea to introduce planned chaos into the curricula which is presented in this article.

Section 2 shows requirements for engineering graduates using surveys among employers. In Section 3, the learning objectives for electrical engineering students are shown. Different curricular concepts are introduced in Section 4, and Section 5 describes the changes in courses when introducing planned chaos. Section 6 shows some first results, and Section 7 gives a summary with conclusion and outlook.

\section{Professional Requirements for Electrical Engineers}

It is obvious that employers expect good theoretical knowledge and first practical experience from graduates. Additional competences are expected depending on the job profile. These have to be also developed during the study program. Several surveys all over the world are repeatedly done to evaluate the required competences.

Most relevant competences beside technical knowledge of graduates are "Communication skills", "Teamwork", "Interpersonal skills" and "Resilience", as an employer survey from the Australian Association of Graduate Employers (2018, p. 48) shows. The National Association of Colleges and Employers (2019a) carries out regular surveys among employers to find out the most important competences of graduates. Based on these evaluations, the career readiness of graduates is defined by the National Association of Colleges and Employers (2019b): "Career readiness is the attainment and demonstration of requisite competencies that broadly prepare college graduates for a successful transition into the workplace." These include interpersonal competencies, for example "Critical Thinking/Problem Solving”, "Oral/Written Communications”, "Teamwork/Collaboration”.

Many studies around the world show similar competence areas that are demanded by employers, like communication, teamwork, problem solving, creativity and the ability for 
lifelong learning. Engineers have to deal with unstructured, real-world problems and have to work in unfamiliar systems (Azmi, Kamin \& Noordin, 2018).

All these from employers demanded skills should be trained within the frame of a study program. An industrial internship during the study program is helpful but not sufficient to gain the required competences. It is necessary to train these competences in diverse lectures and lab courses within the whole study program. Professors should take care of these industrial demands when designing a study program, their lectures and lab courses, and during their daily work with students.

\section{Learning Objectives in Electrical Engineering Education}

Diverse competencies have to be acquired by students during their study programs. The Tuning project categorized these into instrumental, interpersonal and systemic competences (González \& Wagenaar, 2003, pp. 70-73).

The Organization for Economic Co-operation and Development (2005, p. 4) describes a competency as follows: "A competency is more than just knowledge and skills. It involves the ability to meet complex demands, by drawing on and mobilizing psychosocial resources (including skills and attitudes) in a particular context." The European Union (2017, p. 23) describes in their European Qualification Framework (EQF) the responsibility and autonomy that a person has to deal within his or her job. Level 6 says that people should be able to "manage complex technical or professional activities or projects, taking responsibility for decision-making in unpredictable work or study contexts". From Levels 6 of $\mathrm{EQF}$ on, people have to take responsibility for making decisions in unpredictable environments and it is necessary to train this during their study programs.

The difficult term of quality in higher education was reviewed by Schindler, Puls-Elvidge, Welzant and Crawford (2015). There are many different quality definitions available with diverse scopes to stakeholders and views on the institution and many definitions are closely connected to competencies of graduates. The transformative aspect of quality includes the aspects of "Learner-centered approach", "Competency of lectures", "Clarity of outcomes", "Development of critical thinking" and "Student engagement with content" (Schindler et al., 2015, p. 7) that are addressed with this approach of planned chaos. The Purdue University School of Engineering Education defines the competences of their graduated that include "create and synthesize knowledge", "think critically and reflectively" and "demonstrate engineering skills" (Purdue University, 2019). All necessary competences for later work has to be taken into account when designing new curricula (Edwards, SánchezRuiz \& Sánchez-Díaz, 2009). Soft skills are not learned to increase theoretical knowledge but to improve later professional performance. 
An easy way to increase the education of soft skills is to reduce technical courses and replace these with soft skills lectures. There are two drawbacks for this possibility. The first disadvantage is that the technical content of the study program is reduced. Graduates have lower technical skills and are therefore less prepared for highly qualified work. The other disadvantage is that technical lectures and soft skill lectures are separated and so there is no direct interaction within the curriculum. It is difficult for the students to apply their learned soft skills directly in the technical subjects due to the missing connection in curriculum. The key question is, how to integrate the education of relevant soft skills into a curriculum without sacrificing time for technical education and getting maximum learning success for students.

\section{Curricular Concepts}

They are currently many initiatives to find very well structured study programs with very good reproducibility for each student cohort. If this is done in a not appropriate way, it leads to a study program with a high reproducibility for students. They get good grades when they adopt to the study program philosophy, reproduce knowledge and work exactly according to the regulations of the program. It is not the goal that students adopt to the study program but it is the goal that they acquire competencies that are important for their later career. It is questionable if graduates who adopted to a fully structured and defined curriculum are successful in their later career with fluctuating boundary conditions in a fast changing environment. The abstract education goals should be defined and stable over time but the way to these goals should be enhanced with random fluctuations.

On the other side there are initiatives of new teaching methods that include the impacts of non-deterministic environments into teaching concepts. One approach is told by Vicent, Gumara and Fitzgerald (2011) where the teacher should switch from the traditional methods of teaching which are passive for the student to activating teaching models. The Socratic method of questioning students without any evaluation what is right and wrong is used. This is suitable for project based learning within teams to improve their motivation and engagement. Agile didactics is another initiative to improve interaction between students and professors for enhanced learning (Arn, 2017). Unforeseen events can happen due to questions and ideas of learners. Professors should react to these events and use them to shape their lectures. In this way, a real interaction is possible that increases learning success. While several teaching concepts count on unforeseen events and interaction between professors and students, the here described concept introduces unforeseen challenges into a course.

An appropriate starting point for introducing chaos into a course could be a project based lab course. This is a simulation of a practical engineering environment where some amount 
of chaos with unforeseen events of all kinds occur. There are several examples for project based learning in interdisciplinary self-managed student teams. Aznar et al. (2012) described projects between Electronics and Mechanical Engineering students where firstyear students work together to solve real-world projects. Projects of Electrical Engineering and Business students who develop products in a start-up company set-up are described in Fuhrmann and Niemetz (2018). Students search for interesting project topics by themselves and it is therefore not possible to copy projects from former generations. Such projects automatically include some uncertainty about the work schedule, the group dynamics and as a consequence the risk of failure for students. Students are therefore challenged and this increases creativity and engagement for a successful project completion.

\section{Introducing Planned Chaos}

The introduction of planned chaos in lectures and lab courses has not be confused with chaos from insufficient preparation, missing didactic concept and lecturers' chaotic work! Planned chaos within a course is a well-balanced didactic concept with a lot of work. The first and most important prerequisite of all is that the lecturer has to change his or her selfperception. A lecture with a perfect choreography is not the type of lectures where students learn most for their later professional life. Predictable courses induce only a weak need for attention and alertness, as comprehension can safely be postponed to some later point in time, i.e. never. Problem solving, adaptation to unexpected situations, coping with difficult topics skills are not developed at all as everything is predictable in courses.

As students' later working environment will be unstable and sometimes chaotic, a lecture should also prepare for this surrounding. Therefore, a continuously changing environment for students should introduce steady and unforeseeable challenges. It should not be recognized by students as a chaotic course but as a continuously challenging and interesting course.

It is important to find the right amount of challenges for students. If the challenges for students are too low, there is less learning success than possible. If the challenges are too high, students are over-strained, confused and frustrated. This right amount of chaos for an optimal challenge is different for each student, it depends on the learning type, personal prerequisites and the cultural background. Therefore, it is not possible to find a level which is optimal for all students. If there are doubts about the right amount of uncertainty, it should preferably be lower than too high. When supervising a smaller group of students, the amount of uncertainty can be individually adapted by individual discussions with students and selected help.

As an example, a lab course in the bachelor electrical engineering program where students carry out projects in groups together with management students was used to introduce some 
uncertainty (Fuhrmann \& Niemetz, 2018). The students get no detailed instructions about all steps during the semester. They get a short briefing of about $30 . . .45$ minutes with basic background information. Then they have to form groups, find a topic and start to work. All questions should be discussed within the group and if a solution is not possible among the students, the supervisors should be asked. Active engagement of students is therefore absolutely necessary for a successful completion of the project.

Help for students is done according to the didactic principle of "minimal help" to enable students finding own solutions. This is closely related to Maria Montessori's didactic method "Help me to do it myself" (Montessori Jr., 1976, p. 56). Nützel (2019) writes that emotions are important ingredients for learning success. Not necessarily only positive emotions promote learning, also negative emotions can contribute to learning success. Uncertainty and some amount of chaos can contribute to learning success as long as they are resolved by the learners.

\section{Preliminary Results}

It is very challenging to evaluate the use of defined chaos in lectures or lab courses like other evaluations in lectures and labs. The intended introduction of chaos should not be directly visible to students and therefore it can't be included within an overall evaluation of a course like all other directly visible topics.

The project lab described in Section 5 was evaluated by using questions which have be to answered using a five point Lickert scale (Fuhrmann \& Niemetz 2018). Free text answers are welcome for additional remarks and suggestions. Separate evaluations were done for the groups of electrical engineering and business students. Evaluations for the winter semester 2017/18 (Fuhrmann \& Niemetz 2018) and for the winter semester 2018/19 were done. The overall feedback was good to very good, no big differences between the evaluation results for engineering and business students are seen. Students had the impression that the working climate was good, they learned much about their own profession and the profession of the other faculty. Some students complained that they would need more detailed description about their tasks and goals of the project.

During this lab project, the following observations about the uncertainty of the students were made:

- After some initial internal discussions, some groups of students had many questions for the supervisors that led to intense discussions about the project goals.

- Other groups of students made intense research in the internet, and tried to get information from previous groups. Only some questions about project details were asked and no intense discussions evolved. 
- A very limited number of students did not take any action but waited until the supervisors asked them and gave them detailed instructions for the work. This waiting time could last for weeks, no active work from the students was recognized.

It is clear to see that the students deal with this uncertain situation in very different ways. They make the experience during this project that their chosen way directly influences the project success. Supervisors intervened in situations where students were obviously overstrained and were not able to find their own way towards a solution. In the end and after some help of the supervisors, all student projects were successful.

There was an intense discussion with one alumnus about this concept. He said that at the beginning of this practical lab course, he was disappointed and frustrated that he got so little information. In other lectures and practical courses, he was used to get all necessary information at the beginning. At the end of this lab course, he saw this course absolutely positive due to the freedom to carry out own ideas and the high learning success. He sees this course very valuable due to similar situations of uncertainty that he experiences in his daily work.

\section{Summary, Conclusion and Outlook}

The idea for this didactic approach is currently in the starting phase. A preliminary concept was developed and first tests in an electrical measurement lab course were done towards a planned chaos within a project based labs course.

The type and amount of chaos should be adopted according to the type of lecture and study year. It is seen that the right amount of uncertainty is necessary for a high learning success. This optimal amount of uncertainty is different for each student and depends on his or her personality. It is therefore not possible to have the right amount of chaos for all students within a course. It is important to give individual hints according to student's working progress.

Summarized, this model is seen to be an interesting approach with the potential for a didactic method to increase learning outcome for real-world problems. Students learn how to structure the chaos at the beginning of a project. Finding an own way to a solution that no one has found before is always an individual learning success, so no shortcuts are possible.

It is planned to develop this concept of planned chaos further with a critical view on the value to improve learning success. 


\section{References}

Arn, C. (2017). Agile Hochschuldidaktik. 2nd ed. Beltz Juventa.

Australian Association of Graduate Employers. (2018). The AAGE Employer Survey 2019.

Azmi, A. N., Kamin, Y. \& Noordin, M. K. (2018). Competencies of Engineering Graduates: What are the Employer's Expectations? International Journal of Engineering \& Technology, 7(2.29), (pp. 519-523).

Aznar, M., Martinez, M., Zacares, J., Ortega, A., Gonzalez-Espin, F. \& López-Sánchez, J. (2012). Self-managed teams. In Proceedings of the 2012 IEEE Global Engineering Education Conference (EDUCON) (pp. 1-6). IEEE.

Edwards, M., Sánchez-Ruiz, L. M., \& Sánchez-Díaz, C. (2009). Achieving competencebased curriculum in engineering education in Spain. Proceedings of the IEEE, 97(10), (pp. 1727-1736).

European Union. (2017). Council Recommendation of 22 May 2017 on the European Qualifications Framework for lifelong learning and repealing the recommendation of the European Parliament and of the Council of 23 April 2008 on the establishment of the European Qualifications Framework for lifelong learning. Official Journal of the European Union, C 189/15, 2017.

Fuhrmann T. \& Niemetz, M. (2018). Transdisciplinary Bachelor Course Connecting Business and Electrical Engineering. In 4th International Conference on Higher Education Advances (HEAd'18) (pp. 655-663). Universitat Politècnica de València.

González, J. \& Wagenaar, R. (Eds.). (2003). Tuning educational structures in Europe. Bilbao: University of Deusto.

Montessori Jr, M. M. (1976). Education for human development: Understanding montessori. New York: Schocken Books.

National Association of Colleges and Employers. (2019a). The Four Career Competencies Employers Value Most. Retrieved from https://www.naceweb.org/career-readiness/ competencies/the-four-career-competencies-employers-value-most/

National Association of Colleges and Employers. (2019b). Career Readiness for the New College Graduate. Retrieved from https://www.naceweb.org/uploadedfiles/pages/ knowledge/articles/career-readiness-fact-sheet-jan-2019.pdf

Nützel, N. (2019). Lernen mit Gefühl. LMU München. Einsichten. Das Forschungsmagazin, 1, (pp. 28-32).

Organisation for Economic Co-operation and Development. (2005). The definition and selection of key competencies: Executive summary. Paris: OECD.

Purdue University. (2019). Engineering Education Graduate Competencies. Retrieved from https://engineering.purdue.edu/ENE/Academics/Graduate/Competencies

Schindler, L., Puls-Elvidge, S., Welzant, H. \& Crawford, L. (2015). Definitions of quality in higher education: A synthesis of the literature. Higher Learning Research Communications, 5(3), (pp. 3-13).

Vicent, L., Gumara, X. \& Fitzgerald, M. E. (2011). Work in progress - How to provoke creativity and innovation within the classroom by modifying the role of faculty. In 2011 Frontiers in Education Conference (FIE) (pp. T3E-1). IEEE. 